\title{
Development of plant regeneration and Agrobacterium tumefaciens- mediated transformation methodology for Physalis pruinosa
}

\author{
Kerry Swartwood ${ }^{1} \cdot$ Joyce Van Eck ${ }^{1,2}$ (D)
}

Received: 9 August 2018 / Accepted: 13 February 2019 / Published online: 19 February 2019

(c) The Author(s) 2019

\begin{abstract}
Physalis pruinosa, also known as groundcherry, produces a small, yellow, highly nutritious edible fruit that is enveloped by a papery husk. In order for the potential of large-scale production of $P$. pruinosa fruit to be realized, undesirable characteristics, such as an unmanageable, sprawling growth habit and extensive fruit drop, need to be improved by exploiting approaches available through plant breeding, genetic engineering, and gene editing. In this study, we established plant regeneration and Agrobacterium tumefaciens-mediated methods to allow application of genetic engineering and gene editing of P. pruinosa. Cotyledon and hypocotyl explants from 7 to 8-day-old in vitro-grown seedlings were assessed for plant regeneration. Explants were cultured for 2 weeks on a Murashige and Skoog salts-based medium that contained $2 \mathrm{mg} / \mathrm{L}$ zeatin followed by transfer to medium containing $1 \mathrm{mg} / \mathrm{L}$ zeatin. Only hypocotyl explants regenerated shoots. Hypocotyl explants were infected with Agrobacterium tumefaciens strain AGL1 containing the pJL33 binary vector that has the green fluorescent protein reporter and neomycin phosphotransferase II (nptII) selectable marker genes. After cocultivation, explants were cultured on selective plant regeneration medium that contained 50, 100, 200, 250, and $300 \mathrm{mg} / \mathrm{L}$ kanamycin to determine the most effective level for efficient recovery of transgenic lines. Based on PCR analysis for the presence of the nptII gene, medium containing $200 \mathrm{mg} / \mathrm{L}$ kanamycin resulted in the highest transformation efficiency at $24 \%$. This study sets the foundation for future genetic engineering and gene editing approaches for improvement of $P$. pruinosa.
\end{abstract}

\section{Key message}

Methodology for regeneration and transformation of Physalis pruinosa is a key component for the genetic improvement of this underutilized fruit crop for future agricultural production.

Keywords AGL1 · Green fluorescent protein · Groundcherry $\cdot$ Kanamycin $\cdot$ Solanaceae

\author{
Abbreviations \\ GFP Green fluorescent protein \\ GUS Beta-glucuronidase \\ MS Murashige and Skoog \\ nptII Neomycin phosphotranferase II
}

Communicated by Yu-Jin Hao.

Joyce Van Eck

jv27@ cornell.edu

1 Boyce Thompson Institute, 533 Tower Rd., Ithaca, NY 14853, USA

2 Plant Breeding and Genetics Section, School of Integrative Plant Science, Cornell University, Ithaca, NY 14853, USA

\section{Introduction}

The Solanaceae family is comprised of a very diverse group of approximately 3000 species that represent important food crops, ornamentals, and plants with medicinal properties. There is potential for some Solanaceae, including those in the Physalis genera, as new specialty fruit crops, especially in temperate regions, however, trait modification for desirable agronomic characteristic would be needed for agricultural production, (Valdivia-Mares et al. 2016). Within the Solanaceae, Physalis is one of five genera that displays a unique morphological attribute in the form of a papery husk, also referred to as an inflated calyx, that results when sepals elongate and completely envelop the developing fruit (Wang et al. 2015). The husk provides protection from diseases and pests and has also been shown to play a role in carbohydrate 
translocation and fruit development (Fischer and Ludders 1997).

Physalis most recognizable as food crops are groundcherry (P. pruinosa), goldenberry (P. peruviana), and tomatillo $(P$. ixocarpa). P. pruinosa originated in Eastern North America, whereas $P$. peruviana and $P$. ixocarpa originated in Peru and Mexico, respectively (Singh et al. 2014). All three of these Physalis species are primarily consumed as fresh fruit, but $P$. pruinosa and $P$. peruviana are also processed to make jams, juices, raisins, and snack products (Puente et al. 2011).

Physalis pruinosa is of special interest for our work because of its potential as a specialty fruit crop that could provide farmers, namely in temperate regions based on its origins, with an additional source of income that would be further spurred by the growing consumer demand for new and unique fruits (Singh et al. 2014). One advantage of $P$. pruinosa from an agricultural standpoint is it can be grown in a wide variety of soil types with successful crop production even in poor, sandy conditions (Wolff 1991). However, wider adoption as a food crop would be more likely realized through improvements of undesirable agronomic characteristics that would negatively impact agricultural production, especially on a large scale. One such undesirable characteristic, is its sprawling growth habit that would make it unmanageable in production. Another trait for improvement would be fruit size because $P$. pruinosa fruit are very small at approximately $1 \mathrm{~g}$ and $1 \mathrm{~cm}$ in diameter. The fruit ranges from greenish-yellow to golden when ripe depending on the variety and it has a sweeter flavor than tomato, which is another member of the Solanaceae. The fruit are encased in a husk or inflated calyx that forms from elongation of the sepals and turns papery when the fruit are ripe. P. pruinosa is often referred to as groundcherry because the fruit drops to the ground as a result of an abscission zone, similar to the joint found in some tomato pedicels, making harvest difficult (Lee et al. 2018). In addition to the negative aspect of harvestability, gathering fruit from the ground also imposes a food safety risk that could lead to food-borne illness.

Improvement of the less desirable characteristics of $P$. pruinosa, such as growth habit, small fruit size, and fruit drop, would help to increase the likelihood of its broader adoption as a specialty fruit crop. Unfortunately, there is a lack of gene function and genomic information for P. pruinosa that are necessary to develop improvement programs. Expansion of resources is critical for further development of this underutilized solanaceous species as a viable food crop. Perhaps knowledge gained from our work on gene identification, function and trait modification could be applied to improve agronomic characteristics of other underutilized or orphan crops to enhance their agricultural productivity and contribute towards diversification of our food supply especially in regions where people rely on a limited number of sources. Therefore, our efforts have been focused on generation of resources, including a gene delivery method reported here, that will allow these improvements to be put into practice (Lemmon et al. 2018). Our intent for this study was to develop Agrobacterium tumefaciens-mediated transformation methodology for P. pruinosa to facilitate approaches for improvement that include functional studies and application of gene editing technology. In brief, we found that infection of hypocotyl explants from in vitro-grown seedlings was a viable approach for recovery of transgenic lines.

\section{Materials and methods}

\section{Plant material and in vitro seed germination}

Seeds of Physalis pruinosa were obtained from the Solanaceae Germplasm Bank at the Botanical Garden of Nijmegen. To increase the number of seeds to provide the necessary amount for development of transformation methods, seeds were directly sown and germinated in soil in 72-cell inserts in plastic flats that were placed on heat mats in the greenhouse and grown under long-day conditions (16-h light/8-h dark) under natural light supplemented with artificial light from high-pressure sodium bulbs $\left(\sim 250 \mu \mathrm{mol} \mathrm{m}^{-2}\right.$ $\mathrm{s}^{-1}$ ). Daytime and nighttime temperatures were $26-28{ }^{\circ} \mathrm{C}$ and $18-20{ }^{\circ} \mathrm{C}$, respectively, with a relative humidity of 40-60\%. Mature fruits were collected from greenhousegrown $P$. pruinosa plants. To remove the mucilage gel surrounding the seeds extracted from fruit, seeds were pressed against a metal strainer, placed into mesh extraction bags, and soaked in Rapidase C80 KPO (Centerchem.com) for $1-1.5 \mathrm{~h}$. The bag was thoroughly rinsed with water before soaking in $40 \%$ bleach for $10 \mathrm{~min}$ followed by 5-7 rinses, and air-dried at room temperature (approximately $72{ }^{\circ} \mathrm{C}$ ) on paper towels.

Seeds for regeneration and transformation experiments were surface sterilized in $20 \%(\mathrm{v} / \mathrm{v})$ bleach solution containing Tween-20 for 20 min with gentle agitation followed by 3 rinses in sterile deionized water. Surface sterilized seeds were germinated in Magenta ${ }^{\mathrm{TM}} \mathrm{GA}-7$ boxes (from here forward referred to as Magenta boxes) containing $50 \mathrm{~mL}$ of germination medium composed of $2.15 \mathrm{~g} / \mathrm{L}$ Murashige and Skoog (MS) (Murashige and Skoog 1962) salts (Caisson Labs), $100 \mathrm{mg} / \mathrm{L}$ myo-inositol, $2 \mathrm{mg} / \mathrm{L}$ thiamine, $0.5 \mathrm{mg} / \mathrm{L}$ pyridoxine, $0.5 \mathrm{mg} / \mathrm{L}$ nicotinic acid, $10 \mathrm{~g} / \mathrm{L}$ sucrose and $8 \mathrm{~g} / \mathrm{L}$ agar (Sigma-Aldrich, St. Louis, MO). The $\mathrm{pH}$ of the medium was adjusted to 5.8 .

\section{Plant regeneration assessment}

Approximately 7-8 days after the seeds were placed on germination medium, before the first true leaves emerged 
(Fig. 1), cotyledon and hypocotyl explants were excised. To prepare explants, seedlings were placed on a sterile paper towel moistened with sterile deionized water. Cotyledons were excised at the petioles and cut into approximately $0.25-0.5 \mathrm{~cm}$ cross sections. Hypocotyl explants were prepared by cutting immediately below the shoot apex, removing roots, and cutting the remaining hypocotyl into $0.5-1 \mathrm{~cm}$ sections.

Cotyledon and hypocotyl explants were placed onto first phase regeneration medium designated $2 \mathrm{Z}$, which contained $4.3 \mathrm{~g} / \mathrm{L}$ MS salts, $100 \mathrm{mg} / \mathrm{L}$ myo-inositol, $1 \mathrm{~mL} / \mathrm{L}$ of a 1000X solution of modified Nitsch and Nitsch vitamins (per $100 \mathrm{~mL}$ : glycine $0.2 \mathrm{~g}$, nicotinic acid $1 \mathrm{~g}$, pyridoxine- $\mathrm{HCl}$ $0.05 \mathrm{~g}$, thiamine- $\mathrm{HCl} 0.05 \mathrm{~g}$, folic acid $0.05 \mathrm{~g}$, d-biotin $0.004 \mathrm{~g}, \mathrm{pH} 7.0), 20 \mathrm{~g} / \mathrm{L}$ sucrose, $2 \mathrm{mg} / \mathrm{L}$ trans-zeatin, and $5.2 \mathrm{~g} / \mathrm{L}$ TC Gel (Caisson). Cotyledons were placed adaxial side down on the medium. After 2 weeks, coytledon and hypocotyl explants were transferred to second phase plant regeneration medium, $1 \mathrm{Z}$, which contained the same components as $2 \mathrm{Z}$ except that the concentration of trans-zeatin was decreased to $1 \mathrm{mg} / \mathrm{L}$. Petri plates were used for the first transfer to $1 \mathrm{Z}$, but subsequently explants were transferred to fresh media in either petri plates or Magenta boxes depending on the size of the shoots.

When shoots were $2 \mathrm{~cm}$ tall they were excised and transferred to rooting medium designated RM, which contained $4.3 \mathrm{~g} / \mathrm{L}$ MS salts, $1 \mathrm{~mL} / \mathrm{L}$ of a modified Nitsch and Nitsch vitamins solution (see above), $30 \mathrm{~g} / \mathrm{L}$ sucrose, $8 \mathrm{~g} / \mathrm{L}$ Difco Bacto agar (Becton, Dickinson and Company, Franklin Lakes, NJ). Magenta boxes that contained $62.5 \mathrm{~mL}$ of RM were used for the rooting phase.

\section{Agrobacterium strain and binary vector}

The pJL33 binary vector (Floss et al. 2013) was introduced by electroporation into electrocompetent Agrobacterium tumefaciens AGL1 and referred to as AGL1/JL33 (Lazo et al. 1991). pJL33 contains a synthetic version of the gene for green fluorescent protein designated $s G F P$ (S65T) (Chiu et al. 1996) and the neomycin phosphotransferase
(nptII) selectable marker gene, which confers resistance to kanamycin. The Cauliflower Mosaic Virus 35S promoter (CaMV35S) drives expression of $s G F P(S 65 T)$ and $n p t I I$ in pJL33 (Fig. 2).

To prepare for transformation experiments, AGL1/ pJL33 was streaked from a previously prepared glycerol stock maintained at $-80{ }^{\circ} \mathrm{C}$ onto solidified MGL selective medium (Per liter: $5 \mathrm{~g}$ tryptone, $2.5 \mathrm{~g}$ yeast extract, $5 \mathrm{~g} \mathrm{NaCl}$, $5 \mathrm{~g}$ mannitol, $0.1 \mathrm{~g} \mathrm{MgSO}_{4}, 0.25 \mathrm{~g} \mathrm{~K}_{2} \mathrm{HPO}_{4}, 1.2$ g glutamic acid, $15 \mathrm{~g}$ sucrose, $50 \mathrm{mg} / \mathrm{L}$ carbenicillin and $50 \mathrm{mg} / \mathrm{L}$ kanamycin; $\mathrm{pH}$ was adjusted to 7.2, $15 \mathrm{~g}$ Bacto Agar) and maintained at $28{ }^{\circ} \mathrm{C}$ for $48 \mathrm{~h}$. Four single, well-formed colonies were selected, transferred to $50 \mathrm{~mL}$ of liquid LB selective medium, and maintained in a shaking incubator at $28{ }^{\circ} \mathrm{C}$ for $18-24 \mathrm{~h}$ at $250 \mathrm{rpm}$ or the length of time needed to reach an $\mathrm{OD}_{600}$ of 0.6-0.7. The Agrobacterium suspension was centrifuged at $8000 \mathrm{rpm}$ for $10 \mathrm{~min}$ at $20^{\circ} \mathrm{C}$. The pellet was resuspended in $50 \mathrm{~mL}$ of $2 \% \mathrm{MSO}$ medium $(4.3 \mathrm{~g} / \mathrm{L} \mathrm{MS}$ salts, $100 \mathrm{mg} / \mathrm{L}$ myo-inositol, $0.4 \mathrm{mg} / \mathrm{L}$ thiamine, and $20 \mathrm{~g} / \mathrm{L}$ sucrose, $\mathrm{pH}$ to 5.8 ) by vortexing.

\section{Plant transformation and optimization of kanamycin concentration}

One day prior to infection with AGL1/pJL33, hypocotyl explants were excised from 7 to 8-day-old $P$. pruinosa seedlings (before emergence of first true leaves) and cultured on $2 \mathrm{Z}$ medium. For infection, the explants were incubated in the Agrobacterium $/ 2 \%$ MSO suspension for 5 min then transferred to a sterile paper towel to briefly drain excess suspension. The explants were placed back onto $2 \mathrm{Z}$ and cultured in

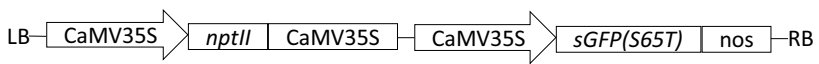

Fig. 2 T-DNA region of the binary vector pJL33 used for Physalis pruinosa transformation. The T-DNA region contains the antibiotic selection marker nptII driven by the CaMV35S promoter. The CaMV35S promoter also drives expression of a synthetic GFP gene, $s G F P$ (S65T) (Chiu et al. 1996)

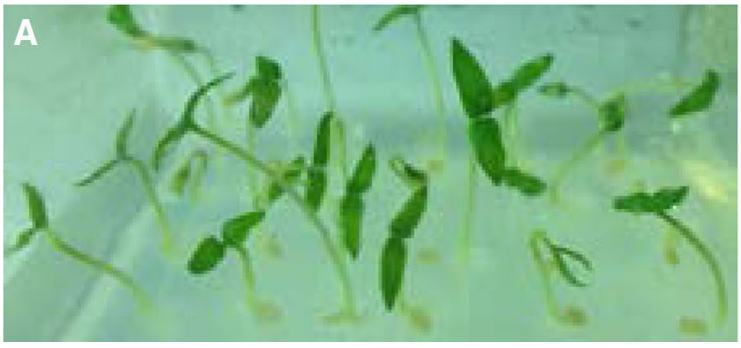

Fig. 1 Response of Physalis pruinosa hypocotyl and cotyledon explants after 5 weeks on plant regeneration medium ( 2 wks on 2Z, 3 wks on 1Z). a Seven-day-od, in vitro-grown seedlings used as a

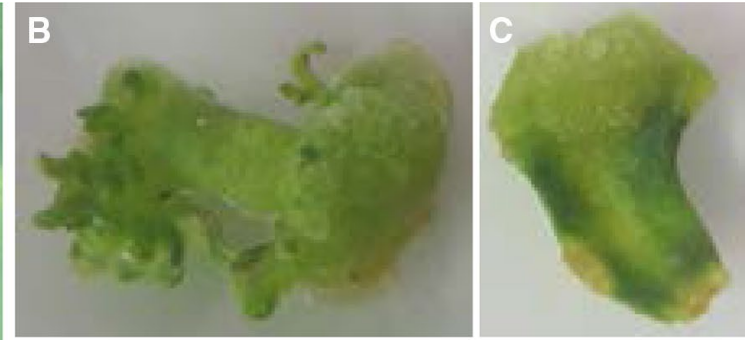

source of cotyledon and hypocotyl explants. b Shoot regeneration from hypocotyl explants. $\mathbf{c}$ Callus formation on cotyledon explants 
the dark at $19{ }^{\circ} \mathrm{C}$ for $48 \mathrm{~h}$. Plates were sealed with parafilm for the cocultivation period.

After $48 \mathrm{~h}$, the explants were transferred to selective $2 \mathrm{Z}$ (designated 2ZK) that contained $300 \mathrm{mg} / \mathrm{L}$ timentin and kanamycin at experimental levels of 50, 100, 200, 250, and $300 \mathrm{mg} / \mathrm{L}$. Two weeks later the explants were transferred to selective $1 \mathrm{ZK}$ medium that contained the same concentrations of timentin and kanamycin as $2 \mathrm{ZK}$ for testing kanamycin sensitivity. Explants were transferred to freshly prepared 1ZK medium every two weeks in either Petri plates or Magenta boxes depending upon size of shoots regenerating from the explants.

A total of 3 different experiments were performed to assess the effect of kanamycin concentration on transformation efficiency. One initial experiment was performed to test $50 \mathrm{mg}$ and $200 \mathrm{mg} / \mathrm{L}$ kanamycin based on 3 biological replicates and a total of 95 hypocotyl explants per concentration. Two subsequent experiments were performed to test the effects of 50,100,200, 250, and $300 \mathrm{mg} / \mathrm{L}$ kanamycin that resulted in 6 biological replicates with a total of 152 hypocotyl explants per concentration. The standard error was calculated.

When regenerated shoots were approximately $2 \mathrm{~cm}$ tall, they were excised from explants and transferred to selective RM (designated RMK) that contained $100 \mathrm{mg} / \mathrm{L}$ kanamycin and $300 \mathrm{mg} / \mathrm{L}$ timentin in Magenta boxes. For acclimation to greenhouse conditions, culture medium was washed from well-rooted plants before transfer to soil. The plants were immediately covered with plastic domes, which were gradually removed over the course of 5 days. Plants were maintained in a growth chamber for 2-3 weeks then transferred to a greenhouse.

Unless otherwise noted, the following conditions were followed. The $\mathrm{pH}$ of all media was adjusted to 6.0 before autoclaving. For all media, trans-zeatin, kanamycin, and timentin were dispensed from filter sterilized stock solutions into autoclaved medium cooled to $55{ }^{\circ} \mathrm{C}$. The size of the Petri plates used was $100 \mathrm{~mm} \times 20 \mathrm{~mm}$. Plates were sealed with Micropore tape (Fisher Scientific, Hampton, NH). All cultures were maintained at $24 \pm 2{ }^{\circ} \mathrm{C}$ under a $16 \mathrm{~h} \mathrm{light} / 8 \mathrm{~h}$ dark photoperiod at $57-65 \mathrm{uE} \mathrm{m}^{-2} \mathrm{~s}^{-1}$.

\section{Green fluorescent protein visualization}

Assessment for green fluorescent protein (GFP) expression was performed at different timepoints from 7 days post infection with AGL1/pJL33, through regeneration of transgenic plants, fruit production, and seeds. Comparisons of putative transgenic material were made with control material (noninfected). All material was examined with an Olympus SZX12 stereo microscope equipped for fluorescence imaging. To visualize GFP expression, an LP Green filter cube was used that had an excitation filter of 470/40 and emission filter of
LP 500. Images were captured with a color CCD camera connected to the ProgRes C14 acquisition software.

\section{DNA extraction and PCR analysis}

Leaf material was used for DNA isolation to facilitate PCR analysis to confirm the presence of the nptII selectable marker gene. In brief, DNA was extracted according to a standard cetyl-trimethyl-ammonium bromide (CTAB) protocol. Following maceration of the tissue in a CTAB buffer, the suspension was treated with chloroform/isoamyl alcohol (24:1) and DNA was precipitated by the addition of isopropanol followed by incubation at $-80 \mathrm{C}$ for $10 \mathrm{~min}$.

Primers used to detect $n p t I I$ were forward 5'-GGC TGG AGA GGC TAT TC-3' and reverse 5'-GGA GGC GAT AGA AGG CG-3'. The diagnostic amplicon size expected with these primers is approximately $735 \mathrm{bp}$. The PCR program started with a one-step cycle of $3 \mathrm{~min}$ at $94{ }^{\circ} \mathrm{C}$, followed by 34 cycles of $30 \mathrm{~s}$ at $94{ }^{\circ} \mathrm{C}, 30 \mathrm{~s}$ at $58^{\circ} \mathrm{C}, 45 \mathrm{~s}$ at $72{ }^{\circ} \mathrm{C}$. DNA was separated and visualized by electrophoresis through a $1.5 \%$ agarose, ethidium bromide-stained gel.

\section{Results}

\section{Plant regeneration from cotyledons and hypocotyls}

P. pruinosa seedlings were at the cotyledon (pre-true leaf) stage 7-8 days after seeds were cultured on germination medium (Fig. 1). Approximately $85 \%$ of the seeds germinated. To test plant regeneration potential from seedling material, cotyledon and hypocotyl segments were cultured on a first phase plant regeneration medium, 2Z, for $2 \mathrm{wks}$, then the second phase, $1 \mathrm{ZK}$. This scheme for plant regeneration, namely the use of zeatin at the indicated concentrations, was based on our experience with tomato because we were unsuccessful at regenerating plants according to reports for other Physalis species 3 (Van Eck et al. 2019). Callus developed along the cut edges of the cotyledon and hypocotyl sections, however, shoots only developed on hypocotyl explants (Fig. 1). Shoots were first observed after approximately 3 weeks on $1 \mathrm{Z}$ medium.

\section{Transformation vector $\mathrm{pJ}$ L33}

We chose the binary vector pJL33 (Floss et al. 2013) (Fig. 2) for development of $P$. pruinosa transformation methodology because it contains a reporter gene cassette for the green fluorescent protein (GFP). The GFP reporter gene, as compared to Beta-glucuronidase (GUS), which requires a destructive assay, allows a more continuous assessment of transformation efficacy at various stages of development post infection with Agrobacterium. pJL33 contains a modified version of 
the GFP gene from the jellyfish (Aequorea victoria) that results in a 20-fold higher expression of GFP in plant cells because of codon usage optimization and replacement of a serine at position 65 with a threonine in the chromophore (Chiu et al. 1996).

\section{Transformation and optimization of kanamycin concentration for selection and rooting of transgenic lines}

Following the 2-day cocultivation of infected material, 25 hypocotyl explants were cultured per Petri plate of 2ZK with 3 replicates per kanamycin concentration $(50,100,200,250$, and $300 \mathrm{mg} / \mathrm{L}$ ) to determine the level that would result in the highest transformation efficiency. Subsequent transfers were done to $1 \mathrm{ZK}$ containing the corresponding kanamycin concentrations. Experiments were performed 2 separate times. Initiation of shoot regeneration was observed approximately 3 wks after transfer to $1 \mathrm{ZK}$. Shoots were transferred to RMK and roots initiated after 5-9 days after transfer. The concentration of kanamycin ( 50 to $300 \mathrm{mg} / \mathrm{L}$ ) affected plant regeneration and transformation efficiency, which ranged from 9 to 24\% (Fig. 3 a-e; Table 1). A set of explants that did not undergo infection was cultured on $2 Z$ followed by $1 Z$ as positive controls. A second set was cultured on $2 \mathrm{ZK}$ and $1 \mathrm{ZK}$ at each concentration of kanamycin to serve as negative controls. Plant regeneration was observed on all positive controls. Plants did not regenerate from negative controls (hypocotyls not infected with A. tumefaciens) (Fig. 3f-j).

Regenerated plants were analyzed by PCR for presence of the nptII gene. We calculated transformation efficiency by dividing the number of plants that were PCR positive by the total number of hypocotyl explants cultured on each concentration of kanamycin (Table 1). In order to ensure we were moving independent transgenic events forward and not sister clones that may have arisen from a single infected cell, only 1 putative transgenic shoot was removed per hypocotyl explant and transferred to selective rooting medium. The highest efficiency, $24 \%$, resulted from infected material cultured on $2 \mathrm{ZK}$ and $1 \mathrm{ZK}$ that contained $200 \mathrm{mg} / \mathrm{L}$ kanamycin (Table 1).

\section{Assessment of transgenesis by GFP visualization and PCR analysis}

GFP expression was used to monitor the progress of transformation and was detected in $P$. pruinosa hypocotyl sections as early as 7 days post infection with AGL1/pJL33. Expression persisted throughout the various stages from callus development through rooted plants (Fig. 4a-c). T0 plants were transferred to soil and grown to maturity in the greenhouse. GFP expression was observed in fruit, husks,
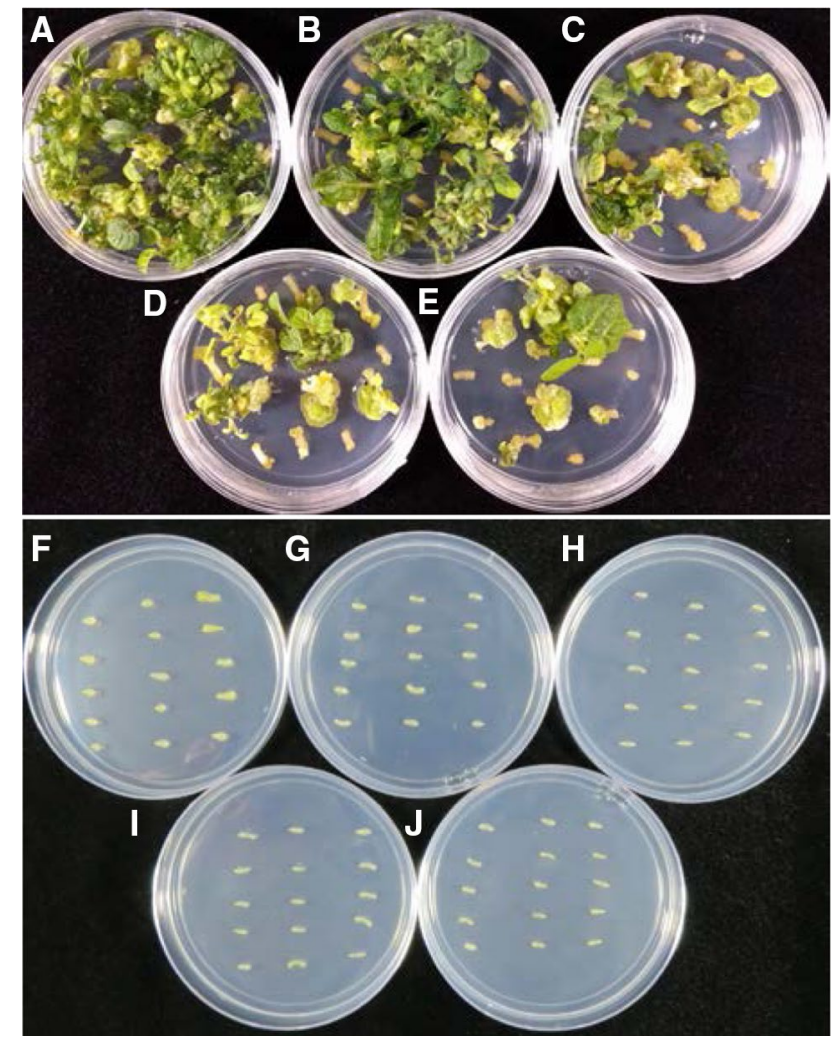

Fig. 3 Determination of an effective kanamycin concentration for selection of transgenic lines from Physalis pruinosa hypocotyl explants infected with Agrobacterium tumefaciens containing pJL33. Upper image: Hypocotyl explants infected with Agrobacterium tumefaciens. Lower image: Negative controls, hypocotyl explants that did not undergo infection with Agrobacterium tumefaciens. Kanamycin concentration (mg/L): a 50, b 100, c 200, d 250, e 300, f 50, g 100, h $200, \mathbf{i} 250, \mathbf{j} 300$

Table 1 Effect of kanamycin concentration on transformation efficiency of Physalis pruinosa

\begin{tabular}{llll}
\hline $\begin{array}{l}\text { Kana- } \\
\text { mycin } \\
(\mathrm{mg} / \mathrm{l})\end{array}$ & $\begin{array}{l}\text { Total number } \\
\text { of hypocotyl } \\
\text { explants }\end{array}$ & $\begin{array}{l}\text { Total number } \\
\text { of PCR positive }_{\text {shoots }^{\mathrm{a}}}\end{array}$ & $\begin{array}{l}\text { Average transfor- } \\
\text { mation efficiency } \\
( \pm) \mathrm{SE}^{\mathrm{b}}\end{array}$ \\
\hline 50 & 247 & 9 & $9.4 \pm 4.30$ \\
100 & 152 & 14 & $9.3 \pm 4.20$ \\
200 & 247 & 33 & $23.6 \pm 4.11$ \\
250 & 152 & 22 & $14.4 \pm 0.95$ \\
300 & 152 & 21 & $13.7 \pm 1.05$ \\
\hline
\end{tabular}

${ }^{\text {a } P C R ~ c o n f i r m a t i o n ~ f o r ~ t h e ~ p r e s e n c e ~ o f ~ t h e ~ n p t I I ~ s e l e c t a b l e ~ m a r k e r ~}$ gene

${ }^{\mathrm{b}}$ Transformation efficiency was calculated as percent of PCR confirmed transgenic lines regenerated from the number of hypocotyl explants infected with Agrobacterium tumefaciens. Efficiency values shown are the average from 2 experiments \pm the standard error (SE) calculated from 6 biological replicate, with the exception of values for 50 and $200 \mathrm{mg} / \mathrm{L}$, which represent 3 experiments and 9 biological replicates 


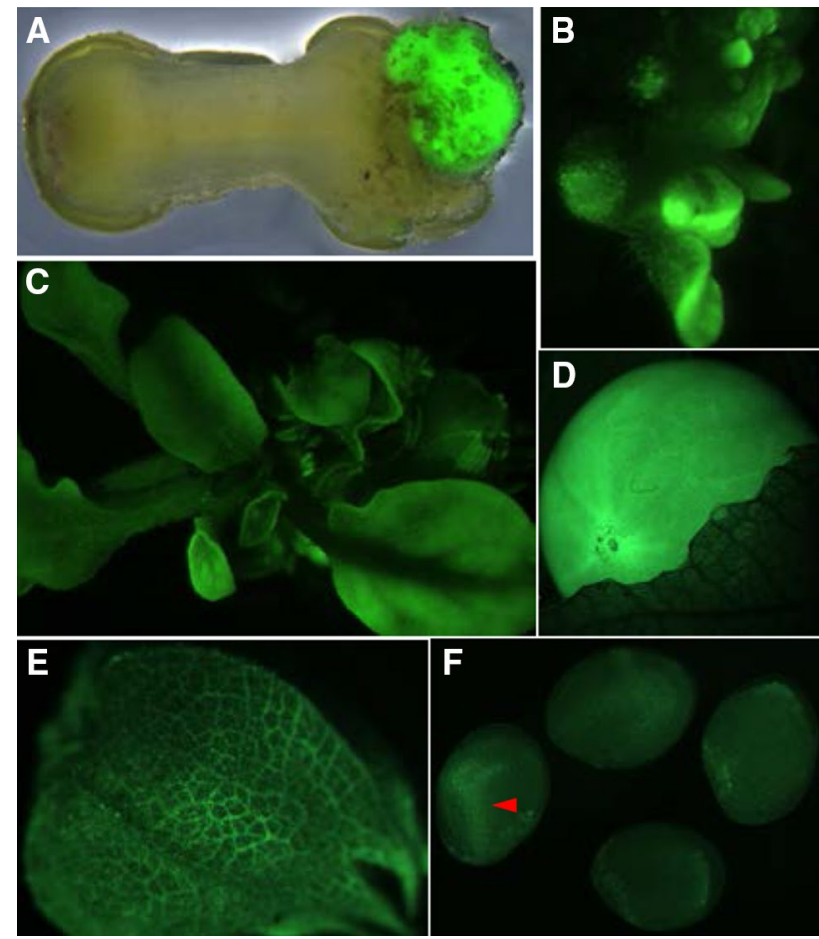

Fig. 4 GFP expression in Physalis pruinosa in vitro and greenhousegrown plant material. a White light and fluorescent overlay image of a hypocotyl with callus 3.5 weeks post infection. b Shoot regeneration from callus 5 weeks post infection. c Whole plant. d Mature fruit. e Husk. f Seeds extracted from fruit. Red arrowhead marks embryo in seed. (Color figure online)

seeds, and most notably, embryos exhibiting GFP were in mature seeds (Fig. 4d-f).

PCR analysis with primers designed to detect the nptII gene was done on DNA isolated from positive control plants recovered from hypocotyl explants that did not undergo infection and putative transgenic lines recovered from explants infected with AGL1/pL33. An amplicon of the expected size ( $735 \mathrm{bp}$ ) was detected in transgenic lines, but not in the controls (Fig. 5).

Based on the work reported here, we established a protocol as outlined in Fig. 6 for A. tumefaciens-mediated transformation of Physalis pruinosa. Following infection of hypocotyl explants, it takes approximately 12 weeks for transgenic lines to be at the stage for transfer to soil. All plants transferred to soil survived the process.

\section{Discussion}

Development of the method reported here was based on our experience with transformation of other Solanaceae family members because although there are reports of plant regeneration and transformation of other Physalis species, we were unsuccessful with application of these methods to

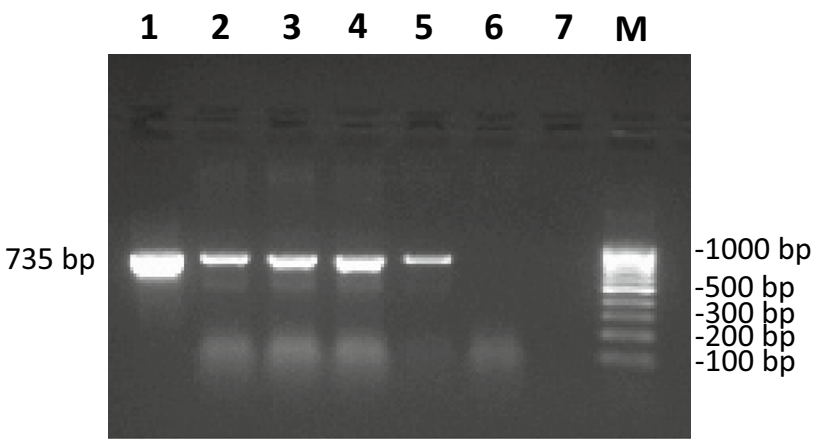

Fig. 5 PCR analysis for detection of the nptII gene. Expected product size of $735 \mathrm{bp}$. Lanes: 1: binary plasmid pJL33 DNA, 2-5: subset of putative transgenic lines; 6: non-transgenic control, 7: blank, M: molecular size marker (100-bp ladder)

P. pruinosa (Otroshy et al. 2013; Simpson et al. 1995; Van Eck et al. 2019; Wang et al. 2011). Therefore, we chose to investigate the applicability of our tomato regeneration and transformation approaches and found these methods to be very effective for P. pruinosa (Van Eck et al. 2019).

As with tomato transformation methodology and reports on transformation of $P$. philadelphica, segments from cotyledons are the explant that works best for A. tumefaciensmediated transformation (Simpson et al. 1995; Van Eck et al. 2019). However, when we investigated plant regeneration

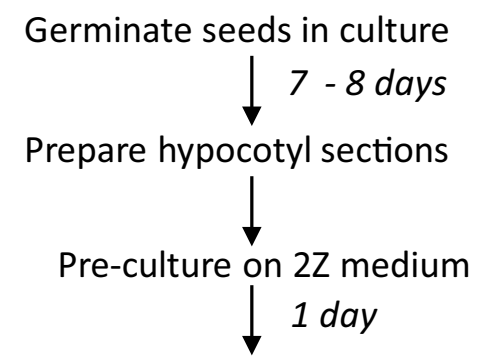

Infect with Agrobacterium AGL1

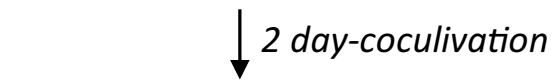

Transfer to 2ZK medium<smiles>C[14CH3]</smiles>

Transfer shoots $1 \mathrm{ZK}$ medium

Transfer shoots RMK medium $\sim 4$ wks first shoots ready for $R M K$ $\sim 3-4 w k s$

\section{Transfer rooted plants to soil}

Fig. 6 Schematic representation of the optimized Agrobacterium tumefaciens-mediated transformation methodology for Physalis pruinosa. See Materials and methods for details on seed sterilization and media composition 
from cotyledon and hypocotyl explants we found that only hypocotyl explants regenerated shoots. These findings of the influence of explant choice on plant regeneration support the importance of evaluating different explant sources when developing a gene-delivery method. Hypocotyls from in vitro-grown seedlings have also been used for A. tumefaciens-mediated transformation of other plant species such as flax and Brassica napus (Dong and McHughen 1993; Jonoubi et al. 2005).

Plant selectable marker genes in vectors are key components in development of efficient transformation methods. There are various types of selectable marker genes, but the most commonly used are those that confer resistance to antibiotics and herbicide components, referred to as selection agents, which are incorporated into the culture medium at some determined point following cocultivation. In the past, we performed sensitivity tests to selection agents by incorporation at various concentrations in the culture medium prior to attempting transformation and monitored for response. However, over time we often observed that sensitivity tests performed pre-transformation did not translate into efficient recovery of transgenic lines. Therefore, we changed our approach and now combine preliminary transformation efforts with sensitivity tests to selection agents as reported here for $P$. pruinosa.

Through incorporation of kanamycin at five different concentrations in the selective plant regeneration media we identified a concentration that resulted in a $24 \%$ transformation efficiency that has been consistent across transformation experiments. The positive effect on transformation efficiency with increasing kanamycin concentration is most likely the result of more efficient inhibition of the growth of non-infected cells that could out-compete infected cells in development. However, as we observed, there is a threshold for the level of kanamycin, in which a high concentration can result in lower transformation efficiency, as evidenced by the decrease in efficiency for $P$. pruinosa hypocotyls cultured on 250 and $300 \mathrm{mg} / \mathrm{L}$. This decrease in efficiency could be explained by nptII expression from pJL33 not being high enough to confer resistance at extreme levels. Effect of kanamycin concentration on transformation efficiency has also been reported for other plant species. For rubber tree, (Heva brasiliensis) transformation was performed that evaluated media containing different kanamycin concentrations. Results showed that the highest efficiency was obtained on medium containing 250-350 mg/L (Jayashree et al. 2003), while concentrations beyond $350 \mathrm{mg} / \mathrm{L}$ resulted in a decrease in transformation efficiency. This result was similar to the effect we observed for $P$. pruinosa once the level of kanamycin was increased beyond $200 \mathrm{mg} / \mathrm{L}$.

In addition to selectable marker genes, reporter genes such as beta-glucuronidase (GUS) and GFP allow progress of each step in the development of transformation methods to be monitored. The ability to assess progress at each step helps to identify where effort is needed for efficient recovery of transgenic lines. The reason we chose pJL33 for development of $P$. pruinosa transformation methodology is that, in addition to containing the $n p t I I$ selectable marker gene that we routinely use for other solanaceous species, it also contains the GFP reporter gene. One advantage of GFP compared to the GUS reporter gene is that assessment of GUS expression requires a destructive assay, whereas visualization of GFP expression is done with fluorescent microscopy allowing tracking development throughout different stages. We were able to track progress of specific transgenic material development from 7 days post infection of hypocotyl explants to callus development to plant regeneration all the way through maturity in the greenhouse. This type of consistent assessment of the same material during the course of methodology development would not have been possible with the GUS reporter gene because of the destructive nature of the assay.

\section{Conclusions}

To our knowledge, this is the first report of Agrobacterium tumefaciens-mediated transformation of Physalis pruinosa, also referred to as groundcherry. Transformation methodology was developed for this underutilized Solanaceae family member as part of our effort to build resources to improve undesirable agronomic characteristics of $P$. pruinosa. Our long-term intent is to promote adoption of $P$. pruinosa as a specialty fruit crop because it has the potential to generate additional income for farmers and provide consumers with a unique fruit crop on a larger scale, however, improvements need to be made for this goal to be realized (Lemmon et al. 2018). Infection of hypocotyl segments from in vitro-grown seedlings followed by culture on selective plant regeneration medium containing an optimized concentration of kanamycin is now a routine approach in our lab for recovery of transgenic lines of $P$. pruinosa. Availability of this efficient transformation methodology will greatly facilitate a better understanding of gene function that will contribute to trait improvement.

Acknowledgements The authors acknowledge the National Science Foundation Plant Genome Research Program (IOS-1732253) for support related to their research on Physalis pruinosa. The authors thank Mamta Srivastava for her guidance with visualization of green fluorescent protein expression, Daniela Floss for providing pJL33, Esperanza Shenstone for assistance with the manuscript, and Zach Lippman for providing the Rapidase.

Author contributions KS and JVE conceived and designed the research. KS conducted the experiments. KS and JVE analyzed the data, contributed towards writing the manuscript, read and approved the manuscript. 


\section{Compliance with ethical standards}

Conflict of interest The authors declare that they have no conflict of interest.

OpenAccess This article is distributed under the terms of the Creative Commons Attribution 4.0 International License (http://creativeco mmons.org/licenses/by/4.0/), which permits unrestricted use, distribution, and reproduction in any medium, provided you give appropriate credit to the original author(s) and the source, provide a link to the Creative Commons license, and indicate if changes were made.

\section{References}

Chiu W-l, Niwa Y, Zeng W, Hirano T, Kobayashi H, Sheen J (1996) Engineered GFP as a vital reporter in plants. Curr Biol 6:325-330

Dong J-Z, McHughen A (1993) An improved procedure for production of transgenic flax plants using Agrobacterium tumefaciens. Plant Sci 88:61-71

Fischer G, Ludders P (1997) Developmental changes of carbohydrates in cape gooseberry (Physalis peruviana $\mathrm{L}$ ) fruits in relation to the calyx and the leaves. Agron Colomb 14:95-107

Floss DS, Levy JG, Levesque-Tremblay V, Pumplin N, Harrison MJ (2013) DELLA proteins regulate arbuscule formation in arbuscular mycorrhizal symbiosis. Proc Natl Acad Sci USA 110:5025-5034

Jayashree R, Rekha K, Venkatachalam P, Uratsu SL, Dandekar AM, Kumari Jayasree P, Kala RG, Priya P, Sushma Kumari S, Sobha S, Ashokan MP, Sethuraj MR, Thulaseedharan A (2003) Genetic transformation and regeneration of rubber tree (Hevea brasiliensis Muell. Arg) transgenic plants with a constitutive version of an anti-oxidative stress superoxide dismutase gene. Plant Cell Rep 22:201-209

Jonoubi P, Mousavi A, Majd A, Salmanian AH, Jalali Javaran M, Daneshian J (2005) Efficient regeneration of Brassica napus L. hypocotyls and genetic transformation by Agrobacterium tumefaciens. Biol Plantarum 49:175-180

Lazo GR, Stein PA, Ludwig RA (1991) A DNA transformation-competent Arabidopsis genomic library in Agrobacterium. Biotechnology 9:963-967

Lee TG, Shekasteband R, Menda N, Mueller LA, Hutton SF (2018) Molecular markers to select for the $\mathrm{j}$-2-mediated jointless pedicel in tomato. Hortscience 53:153-158
Lemmon ZH, Reem N, Dalrymple J, Swartwood KE, Soyk S, Rodriguez-Leal D, Van Eck J, Lippman ZB (2018) Rapid improvement of domestication traits in an orphan crop by genome editing. Nat Plants 4:760-770

Murashige T, Skoog F (1962) A revised medium for rapid growth and bio assays with tobacco tissue cultures. Physiol Plantarum 15:473-497

Otroshy M, Mokhtari A, Mohammad S, Khodaee M, Bazrafshan A (2013) Direct regeneration from leaves and nodes explants of Physalis peruviana L. Intl J Farm Alli Sci 2:214-218

Puente LA, Pinto-Munoz CA, Castro ES, Cortes M (2011) Physalis peruviana Linnaeus, the multiple properties of a highly functional fruit: a review. Food Res Int 44:1733-1740

Simpson J, Montes-Hernandez S, Gutierrez-Campos R, Assad-Garcia N, Herrera-Estrella L (1995) Genetic transformation in Physalis species (tomatillo). In: Bajaj YPS (ed) Plant protoplasts and genetic engineering VI. Springer, Berlin, pp 228-239

Singh DB, Ahmed N, Lal S, Mirza A, Sharma OC, Pal AA (2014) Variation in growth, production and quality attributes of Physalis species under temperate ecosystem. Fruits 69:31-40

Valdivia-Mares LE, Zaragoza FAR, González JJS, Vargas-Ponce O (2016) Phenology, agronomic and nutritional potential of three wild husk tomato species (Physalis, Solanaceae) from Mexico. Sci Hortic-Amsterdam 200:83-94

Van Eck J, Tjahjadi M, Keen P (2019) Agrobacterium tumefaciensmediated transformation of tomato. In: Kumar S, Barone P, Smith M (eds) Transgenic plants: methods and protocols. Springer, New York, pp 225-234

Wang L, Xin M, Qin ZW, Liu HY (2011) Functional analysis of an iaaM gene in parthenocarpic fruit development in transgenic Physalis pubescens L. plants. Plant Cell Tiss Org 107:333-340

Wang L, Li J, Zhao J, He C (2015) Evolutionary developmental genetics of fruit morphological variation within the Solanaceae. Front Plant Sci 6:1-10

Wolff XY (1991) Species, cultivar, and soil amendments influence fruit production of two. Physalis species. Hortscience 26:1558-1559

Publisher's Note Springer Nature remains neutral with regard to jurisdictional claims in published maps and institutional affiliations. 